\title{
Mechanical ventilation in patients with acute ischaemic stroke: from pathophysiology to clinical practice
}

\author{
Chiara Robba ${ }^{1 *}$ (D), Giulia Bonatti ${ }^{1,2}$, Denise Battaglini ${ }^{1,2}$, Patricia R. M. Rocco ${ }^{3}$ and Paolo Pelosi ${ }^{1,2}$
}

\begin{abstract}
Most patients with ischaemic stroke are managed on the ward or in specialty stroke units, but a significant number requires higher-acuity care and, consequently, admission to the intensive care unit. Mechanical ventilation is frequently performed in these patients due to swallowing dysfunction and airway or respiratory system compromise. Experimental studies have focused on stroke-induced immunosuppression and brain-lung crosstalk, leading to increased pulmonary damage and inflammation, as well as reduced alveolar macrophage phagocytic capability, which may increase the risk of infection. Pulmonary complications, such as respiratory failure, pneumonia, pleural effusions, acute respiratory distress syndrome, lung oedema, and pulmonary embolism from venous thromboembolism, are common and found to be among the major causes of death in this group of patients. Furthermore, over the past two decades, tracheostomy use has increased among stroke patients, who can have unique indications for this procedure-depending on the location and type of stroke-when compared to the general population. However, the optimal mechanical ventilator strategy remains unclear in this population. Although a high tidal volume $\left(V_{T}\right)$ strategy has been used for many years, the latest evidence suggests that a protective ventilatory strategy $\left(V_{T}=6-8 \mathrm{~mL} / \mathrm{kg}\right.$ predicted body weight, positive end-expiratory pressure and rescue recruitment manoeuvres) may also have a role in brain-damaged patients, including those with stroke. The aim of this narrative review is to explore the pathophysiology of brain-lung interactions after acute ischaemic stroke and the management of mechanical ventilation in these patients.
\end{abstract}

Keywords: Stroke, Brain injury, Mechanical ventilation, Brain-lung crosstalk, Intensive care unit

\section{Background}

Acute ischaemic stroke (AIS) is one of the major causes of morbidity and mortality worldwide [1] and one of the leading causes for admission to neurological intensive care units (NICUs) [2]. Over the last decades, the incidence of stroke has been increasing, and despite an overall decrease in mortality, it is still the leading cause of severe disability in the adult population [1]. Approximately $80 \%$ of all strokes are ischaemic; other major types include intracerebral (ICH) and intraventricular (IVH) haemorrhage, cerebral venous and sinus thrombosis, and subarachnoid haemorrhage (SAH) secondary

\footnotetext{
* Correspondence: kiarobba@gmail.com

${ }^{1}$ Anesthesia and Intensive Care, San Martino Policlinico Hospital, IRCCS for Oncology and Neurosciences, University of Genoa, Largo Rosanna Benzi, 15, 16100 Genoa, Italy

Full list of author information is available at the end of the article
}

to aneurysm leak or rupture [3]. The location of the stroke is probably the most relevant factor related to the need for mechanical ventilation (MV), rather than the particular type of cerebrovascular pathology. In this context, impairment of the brain areas that regulate the level of consciousness (thalami, the limbic system, the reticular formation in the brainstem), breathing (respiratory centres in the cortex, pons, and medulla), and swallowing (medulla and brainstem connections) increases the risk of respiratory failure [4].

Pulmonary complications-such as respiratory failure, pneumonia, pleural effusion, acute respiratory distress syndrome (ARDS), pulmonary oedema, and pulmonary embolism from venous thromboembolism-may occur in this group of patients and are associated with a high risk of mortality $[5,6]$. In particular, stroke-associated pneumonia (SAP) is described as an independent risk

(c) The Author(s). 2019 Open Access This article is distributed under the terms of the Creative Commons Attribution 4.0 International License (http://creativecommons.org/licenses/by/4.0/), which permits unrestricted use, distribution, and 
factor for unfavourable outcome and death $[7,8]$. Since the most frequent extra-cerebral complication of neurological ICU patients is respiratory failure [5], the development of new mechanical ventilation strategies may potentially improve their outcome [4]. So far, few studies have addressed the best respiratory management of patients with AIS. The aim of this manuscript is to review and describe the pathophysiology underlying the development of pulmonary complications and respiratory failure after AIS and the different ventilator strategies in this population, focusing on the risk related to oxygen $\left(\mathrm{O}_{2}\right)$ therapy and the application of protective lung ventilation. For this purpose, we performed a literature search of four electronic databases (PubMED, Scopus, ScienceDirect, Web of Science), using the following terms: "mechanical ventilation" and "stroke". Titles and abstracts were retrieved and independently assessed for eligibility by two authors (CR, GB). Disagreements were resolved by discussion and consensus agreement and, if required, input from a third author (DB).

This narrative review focuses on the information specific to stroke patients that do not have brain trauma or intracranial pressure issues, including the concern over the need for tracheostomy as an intervention to prevent aspiration pneumonia rather than for primarily pulmonary issues. We also aimed to highlight the different needs of specific subsets of stroke victims that distinct profiles of neurological impairment-such as decreased level of consciousness, cranial nerve deficits, and central swallow concerns-in order to provide a good roadmap to guide the generalist intensivist.

\section{The pathophysiology of stroke and the risk of pulmonary complications Brain-lung crosstalk}

The concept of brain-organ crosstalk has been widely investigated $[9,10]$. Severe brain-damaged patients are commonly unable to protect their airway and therefore are often admitted to the NICU for mechanical ventilation. Prolonged MV is associated with increased risk of developing ventilator-associated lung injury, ARDS, pneumonia, and neurogenic pulmonary oedema [11]. Moreover, ARDS has detrimental effects on the brain, acting synergistically with intracranial hypertension to cause hippocampal damage. A study on rats revealed that focal ischaemic stroke alters the respiratory pattern, induces oedema and inflammation, and decreases the phagocytic capability of alveolar macrophages [6]. Remarkably, all of these changes occurred within $24 \mathrm{~h}$ after the induction of cerebral ischaemia, which is in agreement with the rapid onset of respiratory failure in stroke patients [12].

The mechanism of lung damage after brain injury is described through a "double-hit model": the catecholamine storm and the systemic production of inflammatory mediators (first hit) create a systemic inflammatory environment which increases pulmonary vascular hydrostatic pressure and activates biological mechanisms that make the lung more susceptible to mechanical and non-mechanical insults (second hit), including mechanical ventilation [13]. On the other hand, lung injury can damage the brain through a complex interaction between the autonomic, neuroinflammatory, neuroendocrine, and immunologic pathways [14]. Fries et al. [15] compared pigs with hypoxaemia induced by a lavage model of acute lung injury versus pigs with the same degree of hypoxaemia induced by a reduction in the fraction of inspired oxygen $\left(\mathrm{FiO}_{2}\right)$. Brain damage was greater in the first group, suggesting that acute lung injury per se leads to neuro-pathologic changes regardless of the occurrence of hypoxaemia. The lungs can communicate with the brain through the autonomic and sympathetic nervous system, leading to a neuro-inflammatory process which triggers the activation of the cytokine and complement cascades [16], thus contributing to the development of brain oedema and apoptotic cell death.

\section{Immunological response after stroke}

AIS produces profound local and systemic immune responses that engage all major innate and adaptive immune compartments. After stroke, damage to the blood-brain barrier (BBB) leads to recruitment of resident (astrocytes and microglia) and peripheral (primarily neutrophils and monocytes) immune cells to the affected area [17]. The result is a reduction in circulating immune cells and a depression of peripheral immunity that increases the susceptibility to infections [8]. A large body of experimental and clinical evidence supports the hypothesis of a downregulation of systemic cellular immune responses, with a rapid numerical decrease in peripheral blood lymphocyte subpopulations and functional deactivation of monocytes [18]. These changes are most prominent among patients with larger strokes and are more likely after strokes located in the insular cortex [8]. Experimental and clinical studies in AIS have also reported increased levels of circulating catecholamines and their correlation with lymphopaenia. However, the mechanisms of humoral immunosuppression and bacterial infections remain controversial $[10,19]$. In post-stroke mice, the use of $\beta$ adrenergic receptor antagonists reduces bacterial complications and mortality rates, which may suggest the importance of the catecholamine pathway and vagal response in the immunosuppression process [19] (Figs. 1 and 2).

\section{Stroke-associated pneumonia}

Aspiration pneumonia is one of the major causes of respiratory failure after stroke and can be related to a decreased level of consciousness, with impaired swallowing and dysphagia [8]. However, the incidence of pneumonia in stroke patients is higher when compared to other groups of patients who suffer from dysphagia or compromised level of 


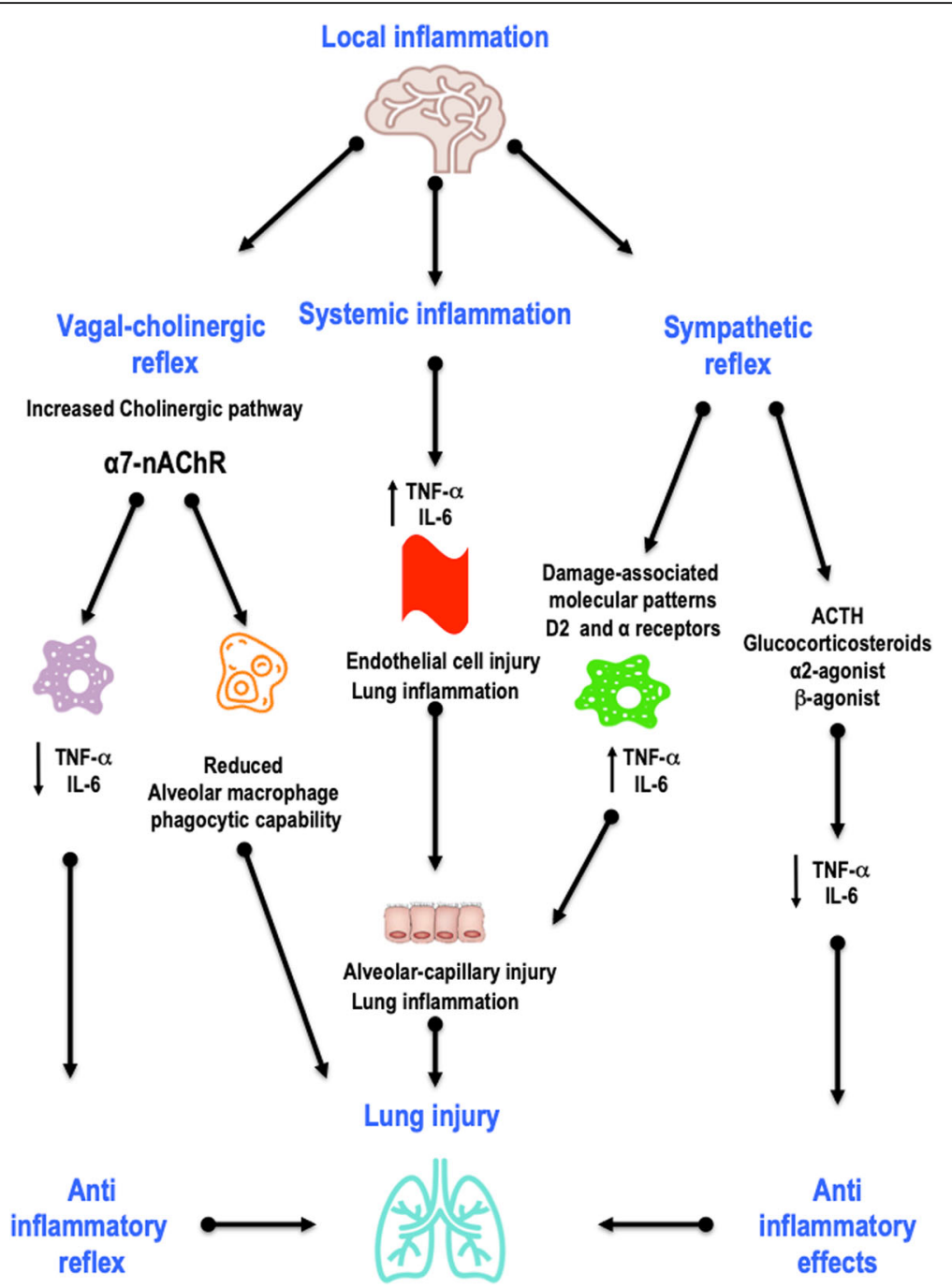

Fig. 1 Brain-systemic crosstalk. After stroke, stimulation of the vagus nerve through nicotinic acetylcholine receptor a7 (nAChRa7) induces microglial activation, causing reduced alveolar macrophage phagocytic capability and reducing circulating levels of interleukin IL-6 and tumour necrosis factor TNF-a, thus leading to an anti-inflammatory reflex and lung injury. On the other hand, systemic inflammation consequent to stroke leads to an increased release of inflammatory mediators such as IL-6 and TNF-a, resulting in lung inflammation and alveolar-capillary injury. Finally, a sympathetic response with increased expression of inflammatory mediators and hypothalamic-pituitary-adrenal axis activation induces elevated glucocorticoid secretion, which might be associated with secondary infections and poor outcome

consciousness, thus suggesting that other mechanisms are involved, such as immune activation and alteration in lung injury pathogenesis [20]. PREDICT, a prospective observational multicentre study, confirmed that both dysphagia and stroke-induced immunodepression syndrome are independent risk factors for aspiration pneumonia [20]. The incidence of SAP ranges between 3.9 and $56.6 \%$, with a higher incidence in the ICU compared to stroke units or wards [8]. Several studies have developed clinical scores to predict SAP with the aim of improving risk stratification in patients with acute stroke [21,22], but their use in the clinical setting is uncommon. In current practice, biomarkers such as C-reactive protein, stroke severity, dysphagia, and the Centres for Disease Control and Prevention criteria
[22] are more frequently used. The most widely recognised measure when acute stroke patients are admitted is nil by mouth status until a swallowing assessment can be completed [8]. Early mobilisation is recommended as it decreases the risk of SAP, while the benefit of antibiotic use in the acute phase remains unproven [23].

\section{Stroke-associated dysphagia}

Prediction of extubation success and safe extubation are important in stroke patients. A prospective observational study [24] that focused on extubation readiness in stroke patients showed that patients who failed in swallowing tests were those who later experienced extubation failure. The reintubation rate was $24.1 \%$, and the main 


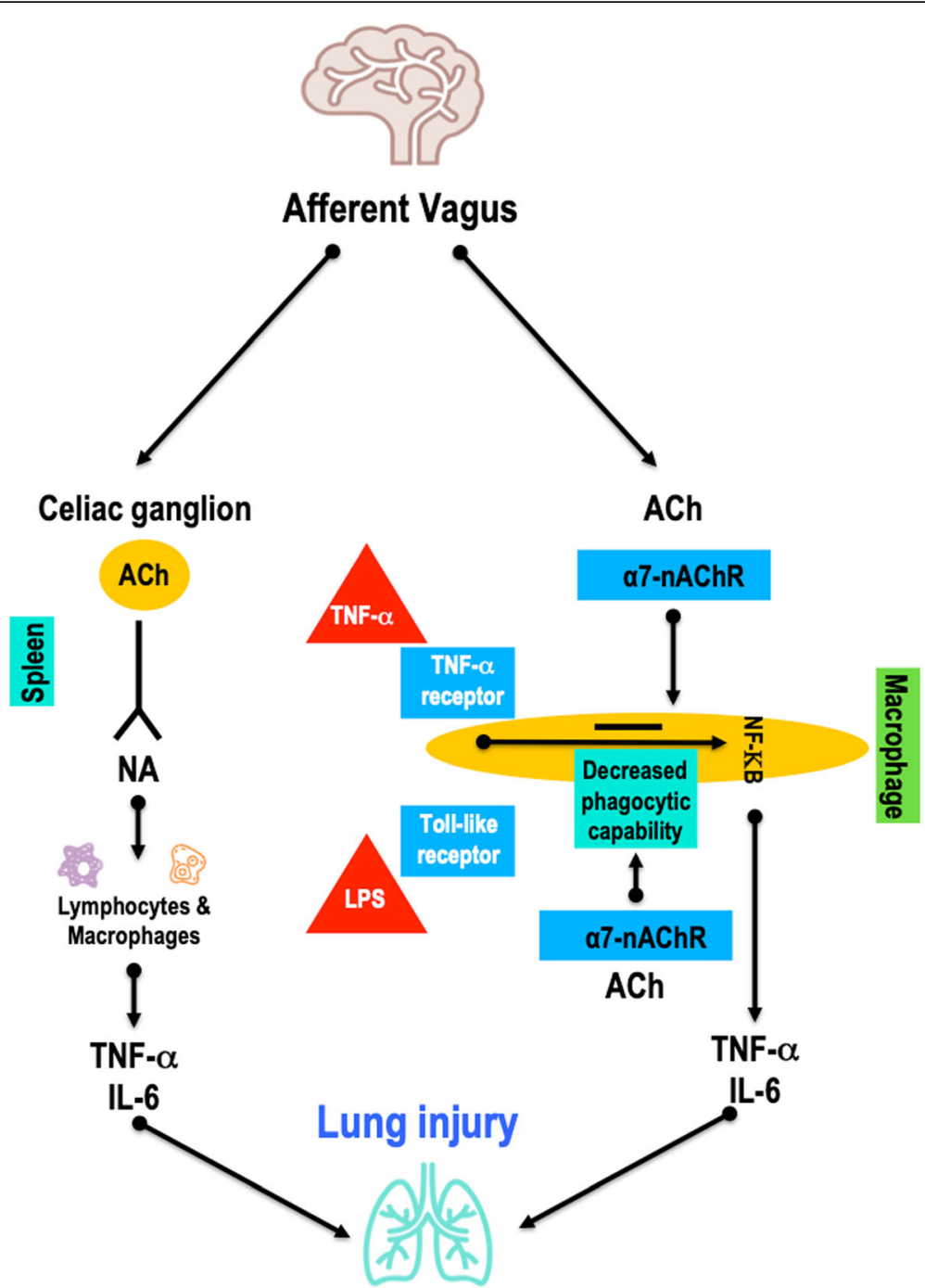

Fig. 2 The role of the vagal pathways in the development of lung injury. The healthy brain can control excess cytokine production via an inflammatory reflex of the vagus nerve (by activation of the afferent vagus through the celiac ganglion). Stimulation of the vagus nerve through nicotinic acetylcholine receptor a7 (nAChRa7) regulates microglial activation in the brain, protects neuronal cells from oxidative stress, and improves functional recovery, contributing to immunosuppression. Expression of nAChRa7 on alveolar macrophages and epithelial cells induces a reduction of inflammation in the lungs, and, by suppressing the production of pro-inflammatory cytokines (IL-6, TNF-a) through

lipopolysaccharides (LPS) and nuclear factor kappa-light-chain-enhancer of activated B cells (NFK-B), impairs host defence during inflammatory conditions. Altogether, vagal stimulation during stroke blunts macrophage capabilities, with increased risk of infection and lung injury, while paradoxically inducing a higher anti-inflammatory response and thus decreasing the risk of lung injury. The balance between these two pathways accounts for the occurrence, or not, of lung injury. Ach, acetylcholine; NA, noradrenaline

determinant of reintubation (in half of these patients) was dysphagia, followed by respiratory complications [24]. Prolonged endotracheal intubation is a major cause of swallowing dysfunction, and the determination of extubation readiness is challenging in this population. The criteria used in the general population for the prediction of extubation failure are based on airway parameters and lung mechanics, whereas in stroke patients, neurological status has a prominent role in the development of dysphagia and is a leading contributor to poor outcome [25]. The prevalence of post-extubation dysphagia ranges from 12 to $69 \%$ in the general ICU population, reaching 93\% in neurological patients [24]. The main causes of post-extubation dysphagia are cerebrovascular disease due to damage to the central swallowing network, pharyngolaryngeal lesions, neuropathies, and myopathies, as well as sedation and mucosal damage [24]. Although several techniques have been developed to diagnose dysphagia, only videofluoroscopy has been considered the goal standard for swallowing dysfunction. An interventional study using fiberoptic endoscopy and including general ICU patients within $48 \mathrm{~h}$ from extubation found that post-extubation 
dysphagia could be diagnosed in $50 \%$ of patients, and the overall incidence of aspiration events was $56 \%$, of which $25 \%$ were silent [25]. This technique demonstrated its utility in the diagnosis of post-extubation dysphagia in 69.3\% of patients [26]. In summary, current evidence agrees on the utility and feasibility of bedside fiberoptic endoscopic swallowing study for assessment of post-extubation dysphagia in patients at risk for aspiration and swallowing dysfunction.

\section{Ventilator settings}

Due to the high incidence of respiratory complications in stroke patients, optimal ventilator management is mandatory [5]. The main goal of MV should be to maintain appropriate oxygen levels and tight control of carbon dioxide tension $\left(\mathrm{PaCO}_{2}\right)$, without inducing ventilator-associated lung damage.

\section{Oxygen therapy}

Hypoxia is common in stroke patients, and an oxygen saturation $\left(\mathrm{SaO}_{2}\right)$ below $90 \%$ in the first few hours after hospital admission is associated with a twofold risk of mortality [27]. Supplemental oxygen could prevent hypoxia and additional neurological deterioration, but it could also lead to adverse effects; in fact, hyperoxia is independently associated with mortality in brain-injured patients, with a higher risk of delayed cerebral ischaemia and poor outcome [28]. Oxygen may increase the risk of respiratory tract infections due to contamination, has a direct effect on vascular tone and blood pressure [29], and at high concentrations, causes vasoconstriction and pulmonary toxicity due to the formation of toxic free radicals. Oxidative stress is also responsible for the activation of cell signalling pathways, inducing apoptosis and neuronal cell death [28, 29]. Evidence from welldesigned trials of oxygen supplementation after acute stroke is conflicting and insufficient to guide clinical practice (Table 1). A quasi-randomised study of oxygen supplementation for acute stroke has shown that routine oxygen therapy in stroke patients does not reduce morbidity and mortality [30]. The Stroke Oxygen Pilot Study $\left(\mathrm{SO}_{2} \mathrm{~S}\right)$, a multicentre randomised controlled trial of oxygen therapy during the first 3 days in patients with acute stroke, compared continuous low-dose oxygen therapy with a nasal cannula at $2-3 \mathrm{~L} / \mathrm{min}$ versus nocturnal lowdose versus usual care (oxygen only when needed) [31]. The authors observed that routine prophylactic low-dose oxygen supplementation did not improve outcome at 3 months [32]. In patients with stroke who have a low arterial oxygen level, adjunctive oxygen treatment is warranted, whereas in non-hypoxic patients, preventive oxygen therapy is not recommended [32] (Table 2). Recent guidelines on the management of traumatic brain injury recommend to set partial pressure of oxygen
$\left(\mathrm{PaO}_{2}\right)$ also considering brain partial tension of oxygen $\left(\mathrm{PbtO}_{2}\right)$ or jugular venous saturation $\left(\mathrm{SjvO}_{2}\right)$ values and to maintain normoxia [33]. For stroke patients, the same recommendations could be acceptable, but specific studies are required. In addition, stroke patients are particularly susceptible to sleep-disordered breathing, with a prevalence of obstructive sleep apnoea ranging from 30 to $80 \%$. A meta-analysis of 29 studies showed that sleep-disordered breathing is present in up to $72 \%$ of stroke patients, whether haemorrhagic or ischaemic, without significant differences between stroke subpopulations. Only $7 \%$ of patients suffered from central sleep apnoea, thus suggesting that young stroke patients are more susceptible to obstructive sleep apnoea than their age-matched peers who have not had a stroke [34]. Therefore, the use of polysomnography, limited channel devices, and auto-continuous positive airway pressure should be implemented for the management of sleep apnoea in patients after a stroke or transient ischaemic attack [34].

\section{Invasive ventilation Intubation}

There are several commonly accepted indications for intubation of neurological patients (Table 3) [45]. In general, the decision to intubate is often triggered by neurological deficits, such as a Glasgow Coma Score $(\mathrm{GCS})<9$, signs of increased intracranial pressure, generalised (tonic-clonic) seizures, infarct size $>2 / 3$ of the middle cerebral artery territory, and midline shift on imaging [23]. Patients with acute brain injury, including stroke, may be at risk for difficult intubation, especially if there is suspicion of associated trauma. Predicting a difficult airway is crucial for the selection of appropriate techniques (i.e. awake fiberoptic versus rapid sequence induction) and tools (video versus direct laryngoscopy) $[46,47]$. In non-emergency settings, awake intubation is the procedure of choice in case of anticipated difficult airway or ventilation, except for patients with elevated intracranial pressure (ICP). In this case, rapid sequence intubation is preferred, since it limits the elevation of ICP induced by laryngoscopy [45]. Adequate oxygenation during intubation is essential for patients with stroke, to prevent secondary injury of the vulnerable brain and further ICP elevation [45-47]. In critically ill patients, $3 \mathrm{~min}$ of pre-oxygenation with non-invasive positive pressure ventilation [48] or a heated high-flow nasal cannula (HHFNC) at $60-70 \mathrm{~L} / \mathrm{min}$ [49] may be more effective than pre-oxygenation with a high-flow (non-rebreather) face mask. However, some evidence suggests the use of apnoeic oxygenation (with HHFNC at $60-70 \mathrm{~L} / \mathrm{min}$ or a nasal cannula at $15 \mathrm{~L} / \mathrm{min}$ ) during laryngoscopy [45, 49]. Indeed, HHFNC was associated with less desaturation in more hypoxaemic patients when compared to positive pressure ventilation [50]. 


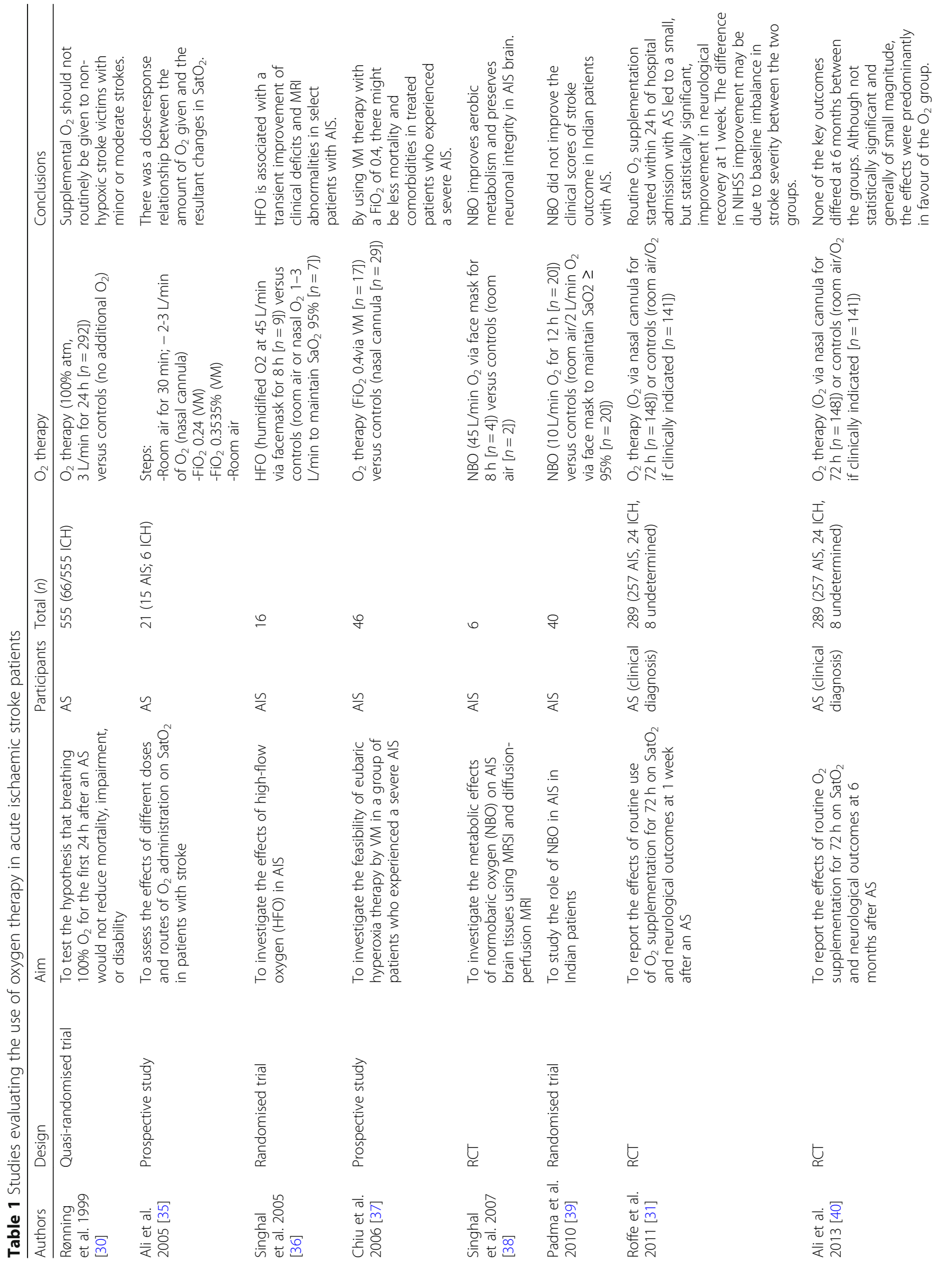




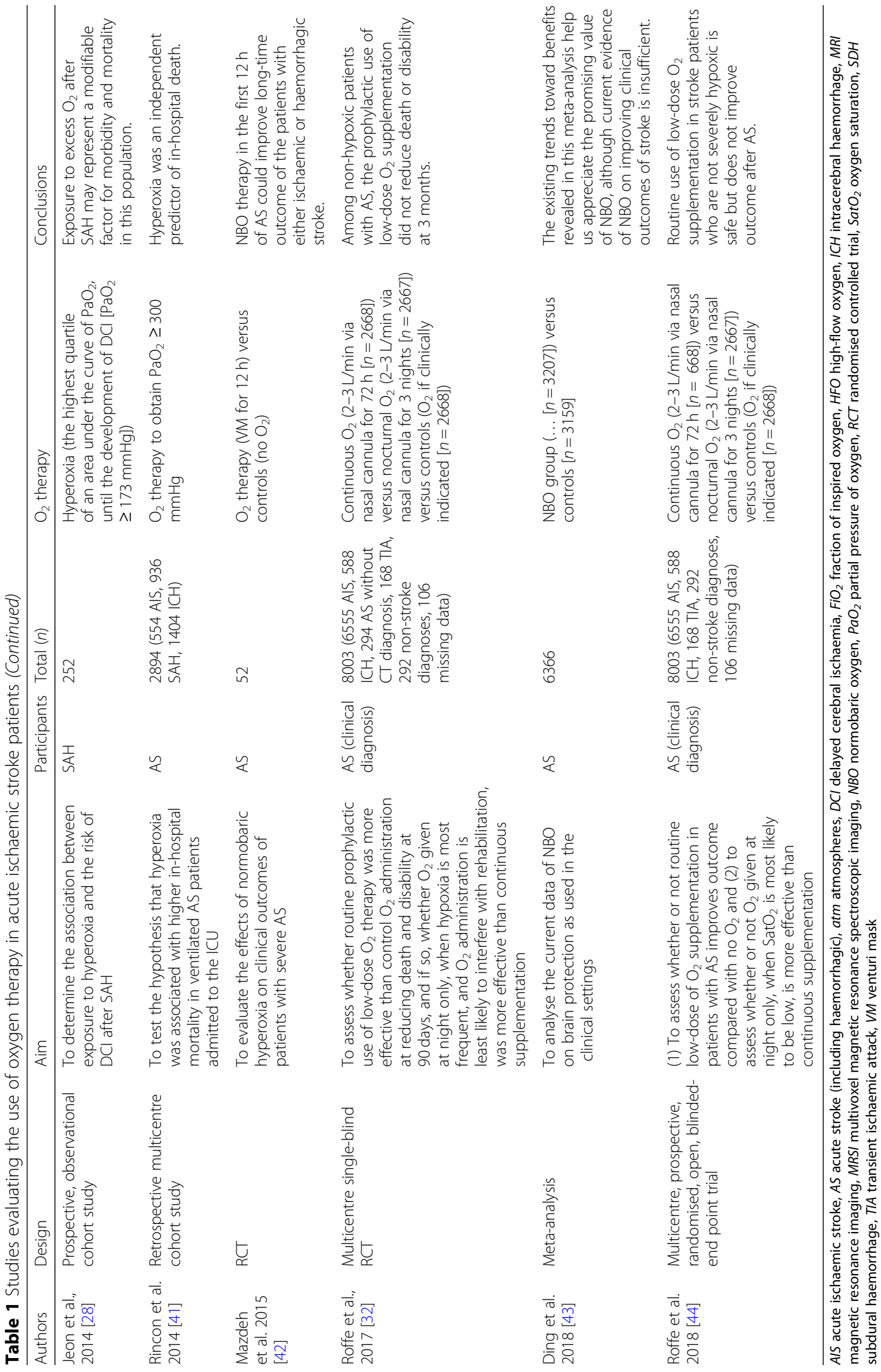


Table 2 Respiratory management of patients with stroke according to 2018 AHA/ASA guidelines [23]

Intubation and ventilation are recommended in patients with decreased consciousness, bulbar dysfunction with inability to protect the airway, or intracranial hypertension (level I).

Aim for normoxia and normocapnia (NA).

Continuous monitoring of oxygenation is strongly recommended in patients with AIS in ICU. Supplemental oxygen should be administered if $\mathrm{SpO}_{2}>94 \%$ (level I).

Supplemental oxygen is not recommended in non-hypoxic patients (level III).

Hyperbaric oxygen is not recommended, except in case of air embolism (level III).

AIS acute ischemic stroke, ICU intensive care unit, $\mathrm{SpO}$ oxygen saturation

Since pre-oxygenation with $100 \%$ oxygen is easy to perform and has no serious adverse effects, its use is recommended during intubation of stroke patients. Once intubation is achieved, oxygen concentration should be decreased immediately to the lowest $\mathrm{FiO}_{2}$ that will result in a $\mathrm{SatO} 2 \geq 95 \%[50]$.

\section{Ventilator settings}

Hypoxaemia and hyper/hypocapnia should be avoided to decrease the risk of secondary brain injury. $\mathrm{PaCO}_{2}$ is a powerful determinant of cerebral blood flow [33]; however, not only hypercapnia is dangerous in stroke patients, but also hyperventilation, because cerebral vasoconstriction can cause brain tissue hypoxia and compromise cerebral compliance and blood flow [51]. No consensus is available regarding the optimal respiratory rate and tidal volume $\left(V_{\mathrm{T}}\right)$ to achieve the $\mathrm{PaCO}_{2}$ target, with higher $V_{\mathrm{T}}$ being generally applied in this group of patients [11]. However, after severe brain injury, higher $V_{\mathrm{T}}$ is associated with both an increased risk of acute lung injury and acute intracranial hypertension $[9,52]$. Similarly, higher driving pressure is associated with a higher risk for ARDS [52]. Moreover, in patients recovered from acute lung injury, the shorter is the inspiratory rise time, the shorter will be the inspiratory work of breathing; also, at $15 \mathrm{cmH}_{2} \mathrm{O}$ of pressure support ventilation, the lowest cycling off criteria

Table 3 Causes of intubation in stroke patients

\begin{tabular}{l}
\hline GCS $<9$ \\
Airway compromise \\
Apnoea \\
Hypoxaemia despite supplemental oxygen \\
Impaired swallowing and gag reflexes \\
Inability to clear secretions \\
Seizures or drugs suppressing respiratory drive \\
Need for intracranial pressure management \\
Anticipated neurological or cardiopulmonary decline requiring transport \\
or immediate treatment
\end{tabular}

GCS Glasgow Coma Scale reduced respiratory rate and increased $V_{\mathrm{T}}$ [53]. In critically ill patients requiring $\mathrm{MV}$, protective ventilation with a $V_{\mathrm{T}}$ of $6 \mathrm{~mL} / \mathrm{kg}$, adequate positive end-expiration pressure (PEEP) levels and limiting plateau pressure to $<30 \mathrm{cmH}_{2} \mathrm{O}$ has shown to reduce absolute mortality by $10 \%$ [54]. However, clinical trials testing ventilation strategies designed for lung protection frequently excluded brain-injured patients; therefore, ventilator management has been scarcely evaluated in neurocritical settings. Indeed, in critically ill patients with acute brain injury, the use of protective lung ventilation is controversial and might even be contraindicated, as it can increase ICP due to permissive hypercapnia and the use of high airway pressures during recruitment manoeuvres [55]. In a porcine model of acute lung injury, major improvement in cerebral oxygenation was observed in animals ventilated with low $V_{\mathrm{T}}$ when compared with high $V_{\mathrm{T}}$ [56]. A multicentre trial with 749 brain-injured patients (36\% in the pre-intervention group and $46 \%$ in the intervention group were stroke patients) [57] suggested that protective ventilation $\left(V_{\mathrm{T}} \leq 7 \mathrm{~mL} / \mathrm{kg}\right.$ of ideal PBW and PEEP 6-8 $\mathrm{cmH}_{2} \mathrm{O}$ ) can significantly improve the number of ventilator-free days at day 90 , as well as reduce the mortality rate. No specific studies focusing on optimal ventilator settings in patients with stroke are available, and only a minority of patients included in the large trials exploring the role of protective ventilation on outcome had stroke; we recommend keeping Pplat between 18 and $25 \mathrm{cmH}_{2} \mathrm{O}$ and minimising respiratory rate to reduce mechanical power. Future studies are needed to better define the optimal $V_{\mathrm{T}}$ in stroke patients requiring MV.

\section{PEEP}

Application of PEEP improves arterial oxygenation. However, in brain-injured patients, caution is warranted because PEEP may worsen or trigger intracranial hypertension [51, 58]. Mascia et al. suggested that ICP increases significantly when PEEP is applied, but only in patients where PEEP induces alveolar hyperinflation with a consequent increase in $\mathrm{PaCO}_{2}$, whereas ICP remains constant when PEEP causes alveolar recruitment with no change in $\mathrm{PaCO}_{2}$ [58]. In an experimental study in both healthy and stroke pigs, high PEEP levels (up to $25 \mathrm{cmH}_{2} \mathrm{O}$ ) did not impair ICP, cerebral oxygenation, or regional cerebral blood flow [59]. Application of high PEEP (up to $20 \mathrm{cmH}_{2} \mathrm{O}$ ) in patients with haemorrhagic stroke resulted in a significant decrease in mean arterial pressure (MAP) and regional cerebral blood flow, but further analyses showed that changes in regional cerebral blood flow depend on MAP changes as a result of impaired cerebrovascular autoregulation [59]. Georgiadis et al. showed that PEEP can be safe in patients with acute stroke, even after increasing PEEP levels up to 12 $\mathrm{mmHg}$, providing that MAP is maintained [60]. In 
addition, a recent trial in non-ARDS patients demonstrated the non-inferiority of a low- $V_{\mathrm{T}}$, low-PEEP strategy as compared to high $V_{\mathrm{T}}$ [61]. Therefore, PEEP is considered safe if (1) haemodynamic status and euvolaemia are maintained to minimise the effects of PEEP on cerebral perfusion pressure and (2) the value of PEEP is lower than ICP, to avoid a decrease in venous outflow [55], thus resulting in a beneficial effect on brain oxygenation [62] while (3) avoiding excessive overdistention and keeping the lung at rest [63].

\section{Recruitment manoeuvres}

Recruitment manoeuvres (RMs) may improve pulmonary gas exchange and respiratory mechanics [64]. However, they may also cause intracranial hypertension by impairing jugular venous outflow and impeding cerebral venous return to the right atrium [64]. In a study by Bein and colleagues of patients with brain injury (6 of 11 were stroke patients) and acute lung injury, volume RMs (which included a 30-s progressive increase in peak pressure up to $60 \mathrm{cmH}_{2} \mathrm{O}$ and a sustained pressure at the same level for the next $30 \mathrm{~s}$ ) led to a deterioration of cerebral oxygenation and, simultaneously, a reduction of MAP and an increase in ICP, with critical reduction of the cerebral perfusion pressure. In 9 brain-injured patients (of whom 6 were stroke patients), a stepwise RM with $3-\mathrm{cmH}_{2} \mathrm{O}$ intermittent increments and decrements of PEEP was applied [65], resulting in a positive correlation between PEEP and ICP and a negative correlation between PEEP and cerebral perfusion pressure (CPP). These data suggest that the effects of PEEP on blood pressure and cerebral perfusion pressure vary greatly in acutely brain-injured patients and that strict MAP and ICP monitoring is of benefit when PEEP is applied. Therefore, RMs could be safely performed when indicated in patients with both stroke and lung injury, especially if setting a PEEP level lower than the ICP and maintaining an effective MAP [66].

\section{Prone positioning}

Similarly to RMs, prone positioning has demonstrated to be an efficient technique to improve oxygenation but should be used cautiously in patients with stroke and reduced intracranial compliance, as it can increase intrathoracic pressure and raise ICP [67]. Only one study investigating the effects of the prone position on respiratory failure provided data on cerebral haemodynamic in patients with stroke, with contradictory results [68]. Thus, the benefits and risks of prone positioning in patients with stroke are still unclear. Nekludov et al. found a significant improvement of pulmonary oxygenation, but a rise in ICP in a group of 8 patients with a GCS $\leq 8$ (3 of them with stroke) and pulmonary injury [67]. Thelandersson and colleagues investigated 11 neurological patients ( 5 of them with stroke) with $\mathrm{FiO}_{2}>0.4$ in prone position for only $3 \mathrm{~h}$, and also found an increase in systemic oxygenation, but unlike the previous study, without significant changes in ICP or MAP [69]. Altogether, prone positioning can present challenges in stroke patients because of the risk of developing intracranial hypertension and displacement of neuromonitoring tools. However, it could be taken into consideration in patients with severe, refractory hypoxaemia and under strict multimodal neuromonitoring.

\section{Other ventilation strategies}

There are insufficient studies to evaluate the role and safety of high-frequency oscillatory ventilation (HFOV) in stroke population. Theoretically, the application of higher mean airway pressures could decrease cerebral venous drainage, and the $\mathrm{PCO}_{2}$ clearance could be insufficient; both aspects are unadvisable in severe braininjured patients. Very few observational studies have evaluated the use of HFOV in adults with acute brain injury, with even fewer focusing on stroke [70]. In a systematic review of the effects of HFOV on cerebral perfusion pressure and intracranial pressure, the authors concluded that, for patients with traumatic brain injury and ARDS, HFOV may improve oxygenation and increase $\mathrm{PaCO}_{2}$. Thus, if HFOV is considered, continuous monitoring of oxygen saturation, MAP, $\mathrm{PaCO}_{2}$, and ICP is paramount [70].

In case of life-threatening hypoxia refractory to conventional MV, the use of rescue therapies has been encouraged to re-establish adequate levels of oxygenation while minimising ventilator-associated injury. In selected cases, extracorporeal lung support techniques have been considered [71].

In summary, in stroke patients requiring $\mathrm{MV}$, protective ventilation with close monitoring of neurological and respiratory variables is essential to ensure lung safety and avoid secondary brain injury. Furthermore, monitoring of cerebral oxygenation should be used when possible to allow the clinician to discriminate between normal and critically impaired tissue oxygenation and help refine ventilator settings $[9,55]$. In future, noninvasive cerebral monitoring could be implemented to individualise ventilator settings [72].

\section{Extubation}

Neurological patients experienced prolonged ICU stays and mechanical ventilation, a higher rate of early tracheostomy, and higher incidence of ventilator-associated pneumonia compared to non-neurological patients [5]. Although often necessary and life-saving, MV is timedependently associated with various complications and may increase morbidity and mortality [73]. Therefore, weaning from mechanical ventilation has been suggested 
to take place as early as is safely possible. Moreover, there is evidence that neurological patients are especially prone to extubation failure, with high reintubation rates, ranging from 20 to 40\% [74]. Prediction of successful extubation is critical, as both delayed and premature extubation increase complication rates need for tracheostomy, duration of ICU stay, and mortality [75]. Unfortunately, classic respiratory predictors for successful extubation in general critical care (such as $V_{\mathrm{T}}$, respiratory rate, negative inspiratory force, forced vital capacity, rapid shallow breathing index, and $\mathrm{PaO}_{2} / \mathrm{FiO}_{2}$ ) are unreliable in braininjured patients [76]. The level of consciousness at the moment of extubation could be considered a risk factor for extubation failure [77], but a recent study [73] showed controversial results. In a meta-analysis [74] specifically looking for predictors of extubation failure in neurocritical care patients, a low GCS (7-9) was identified as a risk factor, with a nearly fivefold increased risk of reintubation. Other factors included the ability to follow commands, secretion texture, and presence of a gag reflex. In a small retrospective study of middle cerebral artery stroke patients, a composite GCS score of 8 with an eye subscore of 4 was associated with successful extubation [78]. However, GCS alone cannot be considered a predictive factor for extubation success, as it has never been validated in intubated patients whose verbal component is impossible to assess and often arbitrarily scored [79]. More recently, Godet et al. [73] developed a clinical score to predict extubation failure in the general brain-injured population with a GCS $<12$ before tracheal intubation, intubated for neurological reasons, and ventilated for more than $48 \mathrm{~h}$; it includes upper airway functions (e.g. gag reflex, cough, and deglutition) and neurological status (evaluated through the visual subscale of the Coma Recovery ScaleRevised). However, external validation of this score is required, and no data specific to stroke patients are available. Recent data have evaluated new physical features in patients with severe brain injury. In a multicentre study, age $<40$ years, visual pursuit, attempts at swallowing, and a GCS $>10$ were found to be predictors of successful extubation [80]. On the basis of these items, the VISAGE score was constructed. If three or more items are positive, an extubation success rate of $90 \%$ can be expected. Visual pursuit and preserved upper airway reflexes [73], younger age [81], negative fluid balance, and the presence of cough have been described as favourable signs of extubation success by other observational studies. Further studies are warranted to confirm the findings of the latest studies on neurological patients in general and stroke in particular.

\section{Tracheostomy}

Up to $45 \%$ of patients admitted to the ICU for stroke require tracheostomy (TT) [81] versus $10-15 \%$ in the general ICU population [5]. Recognised advantages of tracheostomy compared with prolonged oro-tracheal intubation are a reduction of pharyngeal and laryngeal lesions, a better oral hygiene and nursing care, and higher patient comfort [4]. Predictors that may suggest the decision to perform a tracheostomy in stroke patients have been described in few studies [82, 83]. Different types of stroke are associated with the need for tracheostomy, including large hemispheric stroke, basilar thrombosis, brainstem infarction, and spaceoccupying cerebellar stroke [82]. Indeed, the location and extension of brain damage and its secondary effects (including cerebral oedema and secondary ischaemia) may influence the need for MV support. In particular, the compromise of the brain regions which regulate breathing (respiratory centres in the pons, or medulla), level of consciousness (reticular formation, thalami), and swallowing (medulla and brainstem) may lead to respiratory failure and need for tracheostomy [82]. There are two main clinical scenarios in which mechanical ventilation and tracheostomy are usually considered after stroke. The first is in patients with such an extensive stroke that ICU admission and MV are required. In these, long-term ventilation and prolonged insufficient airway protection if extubation fails or is deemed infeasible are the main indications for tracheostomy [82, 83]. The second scenario is in patients with stroke of only moderate overall severity, but which affects the swallowing centres of the brain (such as infarcts of the brainstem or the medulla oblongata), causing dysphagia. In this case, the decision to perform a tracheostomy can be related to severe dysphagia posing a risk of aspiration [84].

In a retrospective study by Szeder et al. [85] on patients with intracranial haemorrhage, features associated with the need for TT were GCS $<9$ at day 3 as well as radiological findings such as hydrocephalus, midline shift, and intraventricular haemorrhage. Schonenberger et al. [83] proposed the stroke-related early tracheotomy (SET) score to screen patients for prolonged intubation and need for TT by combining neurological parameters (e.g. dysphagia and GCS < 10), neuroimaging features (e.g. brainstem lesion, hydrocephalus, intracranial haemorrhage volume $>25 \mathrm{~mL}$ ), general organ function, and surgical procedures. Furthermore, Steidl et al. conducted a two-centre, prospective observational study on both ischaemic and haemorrhagic stroke patients to evaluate the extubation rate over tracheostomy. Overall, $47 \%$ of patients were tracheostomised without any extubation attempt, whereas $53 \%$ were primarily extubated. Among patients primarily tracheotomised, most had haemorrhagic stroke, higher National Institute of Health Stroke Scale, and lower Glasgow Coma scores on admission. Additionally, they received more neurosurgical treatments as compared to those extubated [86]. As can be deduced by the literature, the optimal timing of TT in stroke patients is still unclear. Potential benefits of early TT (such as ventilation duration and length of stay, ventilator weaning, airway safety, rate of pneumonia, outcome, and mortality) have yet to be proven [4]. McCann 


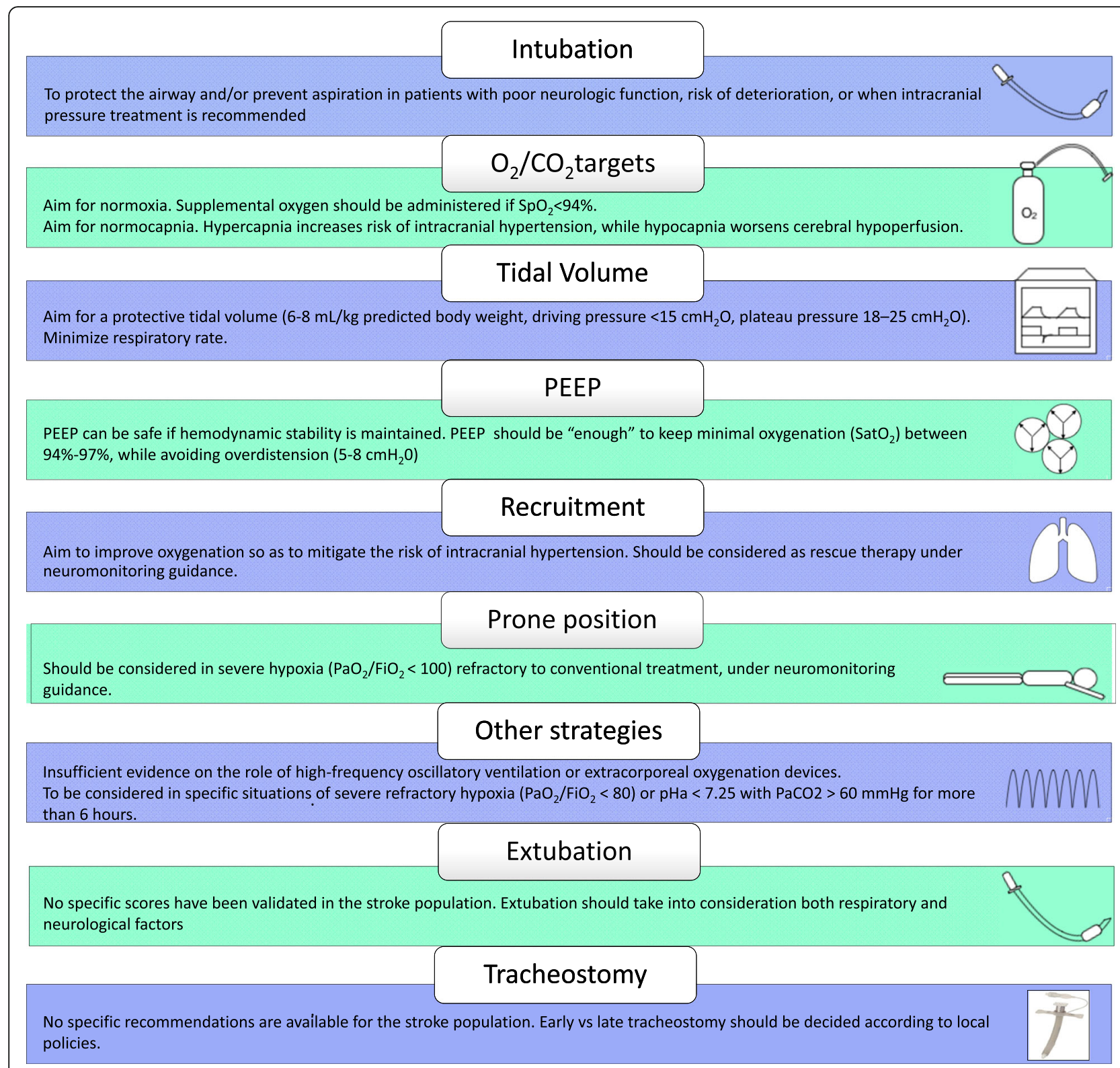

Fig. 3 Recommended mechanical ventilation strategies for patients with acute ischaemic stroke. Abbreviations: PEEP, positive end-expiratory pressure; $\mathrm{O}_{2}$, oxygen; $\mathrm{CO}_{2}$, carbon dioxide

et al. demonstrated a reduced length of stay in patients undergoing earlier (within 1 week) tracheostomy and percutaneous endoscopic gastrostomy (PEG) placement in patients with haemorrhagic stroke [87]. A recent meta-analysis by McCredie et al. evaluated the effect of early versus late TT or prolonged endotracheal intubation in acute brain-injured patients. Ten trials met the selection criteria. Early TT reduced long-term mortality and duration of mechanical ventilation, but insufficient trials were available to perform subgroups analysis; thus, the study refers to the general neuro-ICU population, and no specific data are reported about stroke patients [88]. Overall, as procedural risk is low and early tracheostomy does not seem to affect the clinical course of the ventilated stroke patient, it is suggested that ventilation needs be assessed after the first week of intensive care and tracheostomy considered if an extubation attempt failed or is judged not to be feasible [4].

\section{Recommendations and conclusions}

Although there are no specific data regarding the effect of respiratory management on stroke patients' outcomes, specific ventilator strategies in this population could potentially improve neurologic outcome and prevent respiratory failure by correcting modifiable risk factors or 
controlling brain-induced inflammation of distal organs, mainly the lungs. Protective ventilation has to be considered in this population to obtain the target of normoxia and normocapnia avoiding high $V_{\mathrm{T}}$. Because of the lack of clear evidence and the poor quality of the studies available, clinical decisions regarding ventilator strategies in stroke patients should be made on a case-by-case basis, considering patients' characteristics, risks, and benefits, as well as prognosis and neurological status, using multimodal brain monitoring to assess cerebral haemodynamic and oxygenation and to evaluate the effects of protective ventilation (in particular of $\mathrm{PaCO}_{2}$ and PEEP). We therefore propose a list of recommendations based on the available literature (Fig. 3). Further trials are needed to guide ventilation management in acute ischaemic stroke and to assess possible disparities between the different aetiologies of stroke.

\section{Abbreviations}

ARDS: Acute respiratory distress syndrome; CBF: Cerebral blood flow; ICU: Intensive care unit; AIS: Acute ischaemic stroke; SAH: Subarachnoid haemorrhage; ICH: Intracranial haemorrhage; IVH: Intraventricular haemorrhage; TBI: Traumatic brain injury; MV: Mechanical ventilation; SAP: Stroke-associated pneumonia; PBW: Predicted body weight; $V_{T}$ : Tidal volume; BBB: Blood-brain barrier; MAP: Mean arterial pressure; CNS: Central nervous system; LPS: Lipopolysaccharide; IL-6: Interleukin-6; PEEP: Positive end-expiratory pressure; VAP: Ventilator-associated pneumonia; GCS: Glasgow Coma Scale; $\mathrm{PaO}_{2}$ : Partial pressure of arterial oxygen; ONSD: Optic nerve sheath diameter; ICPPI: Pulsatility index; ICP Fvd: Diastolic velocity; TCD: Transcranial Doppler; $\mathrm{PaCO}_{2}$ : Partial pressure of carbon dioxide; $\mathrm{PbtO}_{2}$ : Brain tissue oxygen tension; TT: Tracheostomy; PDT: Percutaneous dilatational tracheostomy; ST: Open tracheostomy; $\mathrm{EtCO}_{2}$ : End-tidal $\mathrm{CO}_{2}$; $\mathrm{SjvO}_{2}$ : Jugular venous saturation; ESO: European Stroke Organisation; ASA: American Stroke Association; NICE: National Institute for Health and Care Excellence; $\mathrm{CMRO}_{2}$ : Cerebral metabolic rate for oxygen; ICP: Intracranial pressure; NIV: Non-invasive ventilation; HHFNC: Heated high-flow nasal cannula; PEEP: Positive end-expiration pressure; $\mathrm{SaO}_{2}$ : Oxygen saturation; CPP: Cerebral perfusion pressure; Crs: Respiratory system compliance; $\mathrm{FiO}_{2}$ : Inspired oxygen fraction; RM: Recruitment manoeuvres

\section{Acknowledgements}

None

\section{Authors' contributions}

$C R, G B$, and $D B$ wrote the manuscript. $C R$, PP, and $G B$ designed the review. $\mathrm{CR}, \mathrm{GB}, \mathrm{DB}, \mathrm{PRMR}$, and PP revised the manuscript. All authors read and approved the final manuscript.

\section{Funding}

None

\section{Availability of data and materials}

NA

Ethics approval and consent to participate NA

\section{Consent for publication}

NA

\section{Competing interests}

The authors declare that they have no competing interests.

\section{Author details}

${ }^{1}$ Anesthesia and Intensive Care, San Martino Policlinico Hospital, IRCCS for Oncology and Neurosciences, University of Genoa, Largo Rosanna Benzi, 15,
16100 Genoa, Italy. ${ }^{2}$ Department of Surgical Sciences and Integrated Diagnostics, University of Genoa, Genoa, Italy. ${ }^{3}$ Laboratory of Pulmonary Investigation, Carlos Chagas Filho Institute of Biophysics, Federal University of Rio de Janeiro, Rio de Janeiro, Brazil.

Received: 27 July 2019 Accepted: 25 October 2019

Published online: 02 December 2019

\section{References}

1. Krishnamurthi RV, Feigin VL, Forouzanfar MH, Mensah GA, Connor M, Bennett DA, et al. Global and regional burden of first-ever ischaemic and haemorrhagic stroke during 1990-2010: findings from the Global Burden of Disease Study 2010. Lancet Globl Health. 2013;1:e259-81.

2. Backhaus R, Aigner F, Schlachetzki F, Steffling D, Jakob W, Steinbrecher A, et al. Inventory of a neurological intensive care unit: who is treated and how long? Neurol Res Int. 2015;2015:696038.

3. Donnan GA, Fisher M, Macleod M, Davis SM. Stroke. Lancet. 2008;371:1612-23.

4. Bösel J. Use and timing of tracheostomy after severe stroke. Stroke. 2017;48:2638-43.

5. Pelosi P, Ferguson ND, Frutos-Vivar F, Anzueto A, Putensen C, Raymondos K, et al. Management and outcome of mechanically ventilated neurologic patients. Crit Care Med. 2011;39:1482-92.

6. Samary CS, Ramos $A B$, Maia $L A$, et al. Focal ischemic stroke leads to lung injury and reduces alveolar macrophage phagocytic capability in rats. Crit Care. 2018;22:249.

7. Smith CJ, Bray BD, Hoffman A, Meisel A, Heuschmann PU, Wolfe CDA, et al. Can a novel clinical risk score improve pneumonia prediction in acute stroke care? A UK multicenter cohort study. J Am Heart Assoc. 2015;4:e001307.

8. Hannawi Y, Hannawi B, Rao CPV, Suarez Jl, Bershad EM. Stroke-associated pneumonia: major advances and obstacles stroke-associated pneumonia. Cerebrovasc Dis. 2013;35:430-43.

9. Pelosi P, Rocco PRM. The lung and the brain: a dangerous cross-talk. Crit Care. 2011;15:168.

10. Samary CS, Pelosi P, Leme Silva P, Rocco PRM. Immunomodulation after ischemic stroke: potential mechanisms and implications for therapy. Crit Care. 2016;20:391.

11. Asehnoune K, Roquilly A, Cinotti R. Respiratory management in patients with severe brain injury. Crit Care. 2018;22:76.

12. Duan J, Bai L, Zhou L, Han X, Huang S. Decreasing re-intubation using prophylactic noninvasive ventilation in elderly patients: a propensitymatched study. J Crit Care. 2019;50:77-81.

13. Mascia L. Acute lung injury in patients with severe brain injury: a double hit model. Neurocrit Care. 2009;11:417-26.

14. Stevens RD, Puybasset L. The brain-lung-brain axis. Intensive Care Med. 2011;37:1054-6.

15. Fries $M$, Bickenbach J, Henzler D, Beckers S, Dembinski R, Sellhaus B, et al. S100 protein and neurohistopathologic changes in a porcine model of acute lung injury. Anesthesiology. 2005;102:761-7.

16. Hegeman MA, Hennus MP, Heijnen CJ, Specht PA, Lachmann B, Jansen NJ, et al. Ventilator-induced endothelial activation and inflammation in the lung and distal organs. Crit Care. 2009;13:R182.

17. Tsai AS, Berry K, Beneyto MM, Gaudilliere D, Ganio EA, Culos A, et al. A yearlong immune profile of the systemic response in acute stroke survivors. Brain. 2019;142:978-91.

18. Chamorro Á, Meisel A, Planas AM, Urra X, Van De Beek D, Veltkamp R. The immunology of acute stroke. Nat Rev Neurol. 2012;8:401-10.

19. Prass K, Meisel C, Höflich C, Braun J, Halle E, Wolf T, et al. Stroke-induced immunodeficiency promotes spontaneous bacterial infections and is mediated by sympathetic activation reversal by poststroke T helper cell type 1-like immunostimulation. J Exp Med. 2003;198:725-36.

20. Hoffmann S, Harms H, Ulm L, Nabavi DG, Mackert BM, Schmehl I, et al. Stroke-induced immunodepression and dysphagia independently predict stroke-associated pneumonia - the PREDICT study. J Cereb Blood Flow Metab. 2017;37:3671-82.

21. Zapata-Arriaza E, Moniche F, Blanca P-G, Bustamante A, EscuderoMartínez I, Uclés O, et al. External validation of the ISAN, A2DS2, and AIS-APS scores for predicting stroke-associated pneumonia. J Stroke Cerebrovasc Dis. 2018;27:673-6.

22. Horan TC, Andrus M, Dudeck MA. CDC/NHSN surveillance definition of health care-associated infection and criteria for specific types of infections in the acute care setting. Am J Infect Control. 2008;36:309-32. 
23. Powers WJ, Rabinstein AA, Ackerson T, Adeoye OM, Bambakidis NC, Becker K, et al. 2018 Guidelines for the Early Management of Patients With Acute Ischemic Stroke: a guideline for healthcare professionals from the American Heart Association/American Stroke Association. Stroke. 2018;49:e46-110.

24. Suntrup-Krueger S, Schmidt S, Warnecke T, Steidl C, Muhle P, Schroeder JB, et al. Extubation readiness in critically ill stroke patients. Stroke. 2019;50:1981-8.

25. Ajemian MS, Nirmul GB, Anderson MT, Zirlen DM, Kwasnik EM. Routine fiberoptic endoscopic evaluation of swallowing following prolonged intubation: implications for management. Arch Surg. 2001;136:434-7.

26. Hafner G, Neuhuber A, Hirtenfelder S, Schmedler B, Eckel HE. Fiberoptic endoscopic evaluation of swallowing in intensive care unit patients. Eur Arch Otorhinolaryngol. 2008;265:441-6.

27. Rowat AM, Dennis MS, Wardlaw JM. Hypoxaemia in acute stroke is frequent and worsens outcome. Cerebrovasc Dis. 2006;21:166-72.

28. Jeon SB, Choi HA, Badjatia N, Schmidt JM, Lantigua H, Claassen J, et al. Hyperoxia may be related to delayed cerebral ischemia and poor outcome after subarachnoid haemorrhage. J Neurol Neurosurg Psychiatry. 2014;85:1301-7.

29. Floyd TF, Clark JM, Gelfand R, Detre JA, Ratcliffe S, Guvakov D, et al. Independent cerebral vasoconstrictive effects of hyperoxia and accompanying arterial hypocapnia at 1 ATA. J Appl Physiol. 2003;95:2453-61.

30. Rønning OM, Guldvog B. Should stroke victims routinely receive supplemental oxygen? Stroke. 1999;30:2033-7.

31. Roffe C, Ali K, Warusevitane A, Sills S, Pountain S, Allen M, et al. The SOS pilot study: a RCT of routine oxygen supplementation early after acute stroke--effect on recovery of neurological function at one week. PLoS One. 2011;6:e19113.

32. Roffe C, Nevatte T, Sim J, Bishop J, Ives N, Ferdinand P, et al. Effect of routine low-dose oxygen supplementation on death and disability in adults with acute stroke: the stroke oxygen study randomized clinical trial. JAMA. 2017:318:1125-35.

33. Carney N, Totten AM, O'reilly C, Ullman JS, Hawryluk GWJ, Bell MJ, et al. Brain Trauma Foundation TBI guidelines for the management of severe traumatic brain injury, fourth edition. Neurosurgery. 2017;80:6-15.

34. Johnson KG, Johnson DC. Frequency of sleep apnea in stroke and TIA patients: a meta-analysis. J Clin Sleep Med. 2010;6:131-7.

35. Ali K, Sills S, Roffe C. The Effect of Different Doses of Oxygen Administration on Oxygen Saturation in Patients With Stroke. Neurocrit Care. 2005;3(1):024-26.

36. Singhal AB, Benner $T$, Roccatagliata L, Koroshetz WJ, Schaefer PW, Lo EH, Buonanno FS, Gonzalez RG, Sorensen G. A Pilot Study of Normobaric Oxygen Therapy in Acute Ischemic Stroke. Stroke. 2005;36(4):797-802.

37. Chiu EH, Liu CS, Tan TY, Chang KC. Venturi Mask Adjuvant Oxygen Therapy in Severe Acute Ischemic Stroke. Arch Neurol. 2006;63(5):741.

38. Singhal AB, Ratai E, Benner T, Vangel M, Lee V, Koroshetz WJ, Schaefer PW, A. Gregory Sorensen, R, Gonzalez, G. Magnetic Resonance Spectroscopy Study of Oxygen Therapy in Ischemic Stroke. Stroke. 2007;38(10):2851-854

39. Padma MV, Bhasin A, Bhatia R, Garg A, Singh MB, Tripathi M, Prasad K. Normobaric oxygen therapy in acute ischemic stroke: A pilot study in Indian patients. Ann Indian Acad Neurol. 2010;13(4):284

40. Ali K, Warusevitane A, Lally F, Sim J, Sills S, Pountain S, Nevatte T, Allen M, Roffe C, Kleinschnitz, C. The Stroke Oxygen Pilot Study: A Randomized Controlled Trial of the Effects of Routine Oxygen Supplementation Early after Acute Stroke-Effect on Key Outcomes at Six Months. PLoS ONE. 2013; 8(6):e59274

41. Rincon F, Kang J, Maltenfort M, Vibbert M, Urtecho J, Athar MK, Jallo J, Pineda CC, Tzeng D, McBride W, Bell R. Association Between Hyperoxia and Mortality After Stroke: A Multicenter Cohort Study. Neurologic Critical Care. 2014;42(2):387-96.

42. Mazdeh M, Taher A, Torabian S, Seifirad S. Effects of Normobaric Hyperoxia in Severe Acute Stroke: a Randomized Controlled Clinical Trial Study. Acta Med Iran. 2015;53(11):676-80.

43. Ding J, Zhou D, Sui M, Meng R, Chandra A, Han J, Ding Y, Ji X. The effect of normobaric oxygen in patients with acute stroke: a systematic review and meta-analysis. Neurol Res. 2018:40(6):433-44.

44. Roffe C, Nevatte T, Bishop J, Sim J, Penaloza C, Jowett S, Ives N, Gray R, Ferdinand P, Muddegowda G. Routine low-dose continuous or nocturnal oxygen for people with acute stroke: three-arm Stroke Oxygen Supplementation RCT. Health Technology Assessment. 2018; 22(14):1-88.

45. Rajajee V, Riggs B, Seder DB. Emergency neurological life support: airway, ventilation, and sedation. Neurocrit Care. 2017;27(Suppl 1):4-28.

46. Jaber S, De Jong A, Pelosi P, Cabrini L, Reignier J, Lascarrou JB. Videolaryngoscopy in critically ill patients. Crit Care. 2019;23:221.
47. Cabrini L, Landoni G, Baiardo Radaelli M, Saleh O, Votta CD, Fominskiy E, et al. Tracheal intubation in critically ill patients: a comprehensive systematic review of randomized trials. Crit Care. 2018;22:6.

48. Baillard C, Fosse J-P, Sebbane M, Chanques G, Vincent F, Courouble $P$, et al. Noninvasive ventilation improves preoxygenation before intubation of hypoxic patients. Am J Respir Crit Care Med. 2006;174:171-7.

49. Mosier JM, Hypes CD, Sakles JC. Understanding preoxygenation and apneic oxygenation during intubation in the critically ill. Intensive Care Med. 2017;43:226-8.

50. Frat J-P, Ragot S, Girault C, Perbet S, Prat G, Boulain T, et al. Effect of noninvasive oxygenation strategies in immunocompromised patients with severe acute respiratory failure: a post-hoc analysis of a randomised trial. Lancet Respir Med. 2016;4:646-52.

51. Borsellino B, Schultz MJ, Gama de Abreu M, Robba C, Bilotta F. Mechanical ventilation in neurocritical care patients: a systematic literature review. Expert Rev Respir Med. 2016:10:1123-32.

52. Tejerina E, Pelosi P, Muriel A, Peñuelas O, Sutherasan $Y$, Frutos-Vivar F, et al. Association between ventilatory settings and development of acute respiratory distress syndrome in mechanically ventilated patients due to brain injury. J Crit Care. 2017;38:341-5.

53. Chiumello D, Pelosi P, Taccone P, Slutsky A, Gattinoni L. Effect of different inspiratory rise time and cycling off criteria during pressure support ventilation in patients recovering from acute lung injury. Crit Care Med. 2003;31:2604-10.

54. Acute Respiratory Distress Syndrome Network, Brower RG, Matthay MA, Morris A, Schoenfeld D, Thompson BT, et al. Ventilation with lower tidal volumes as compared with traditional tidal volumes for acute lung injury and the acrte respiratory distress syndrome. N Engl J Med. 2000;342:1301-8.

55. Mazzeo AT, Fanelli V, Mascia L. Brain-lung crosstalk in critical care: how protective mechanical ventilation can affect the brain homeostasis. Minerva Anestesiol. 2013;79:299-309.

56. Bickenbach J, Zoremba N, Fries M, Dembinski R, Doering R, Ogawa E, et al. Low tidal volume ventilation in a porcine model of acute lung injury improves cerebral tissue oxygenation. Anesth Analg. 2009;109:847-55.

57. Asehnoune K, Mrozek S, Perrigault PF, Seguin P, Dahyot-Fizelier C, Lasocki S, et al. A multi-faceted strategy to reduce ventilation-associated mortality in brain-injured patients. The BI-VILI project: a nationwide quality improvement project. Intensive Care Med. 2017:43:957-70.

58. Mascia L, Grasso S, Fiore T, Bruno F, Berardino M, Ducati A. Cerebropulmonary interactions during the application of low levels of positive endexpiratory pressure. Intensive Care Med. 2005;31:373-9.

59. Muench E, Bauhuf C, Roth H, Horn P, Phillips M, Marquetant $N$, et al. Effects of positive end-expiratory pressure on regional cerebral blood flow, intracranial pressure, and brain tissue oxygenation. Crit Care Med. 2005;33:2367-72.

60. Georgiadis D, Schwarz S, Baumgartner RW, Veltkamp R, Schwab S. Influence of positive end-expiratory pressure on intracranial pressure and cerebral perfusion pressure in patients with acute stroke. Stroke. 2001;26:174-81.

61. Algera AG, Pisani L, Bergmans DCJ, den Boer S, de Borgie CAJ, Bosch FH, et al. RELAx - REstricted versus liberal positive end-expiratory pressure in patients without ARDS: protocol for a randomized controlled trial. Trials. 2018;19:272.

62. Nemer SN, Caldeira JB, Santos RG, et al. Effects of positive end-expiratory pressure on brain tissue oxygen pressure of severe traumatic brain injury patients with acute respiratory distress syndrome: a pilot study. J Crit Care. 2015:30:1263-6.

63. Pelosi P, Rocco PRM, Gama de Abreu M. Close down the lungs and keep them resting to minimize ventilator-induced lung injury. Crit Care. 2018;22:72.

64. Nemer SN, Caldeira JB, Azeredo LM, Garcia JM, Silva RT, Prado D, et al. Alveolar recruitment maneuver in patients with subarachnoid hemorrhage and acute respiratory distress syndrome: a comparison of 2 approaches. J Crit Care. 2011;26:22-7.

65. Zhang $X$, Yang Z, Wang Q, Fan $\mathrm{H}$. Impact of positive end-expiratory pressure on cerebral injury patients with hypoxemia. Am J Emerg Med. 2011;29:699-703.

66. Lowe GJ, Ferguson ND. Lung-protective ventilation in neurosurgical patients. Curr Opin Crit Care. 2006;12(1):3-7.

67. Nekludov M, Bellander B-M, Mure M. Oxygenation and cerebral perfusion pressure improved in the prone position. Acta Anaesthesiol Scand. 2006;50: 932-6.

68. Roth C, Ferbert A, Deinsberger W, et al. Does prone positioning increase intracranial pressure? A retrospective analysis of patients with acute brain injury and acute respiratory failure. Neurocrit Care. 2014;21:186-91. 
69. Thelandersson A, Cider $\AA$, Nellgård B. Prone position in mechanically ventilated patients with reduced intracranial compliance. Acta Anaesthesiol Scand. 2006;50:937-41.

70. Simonis FD, Binnekade JM, Braber A, Gelissen HP, Heidt J, Horn J, et al. PReVENT - protective ventilation in patients without ARDS at start of ventilation: study protocol for a randomized controlled trial. Trials. 2015;16:226.

71. Bein T, Scherer MN, Philipp A, Weber F, Woertgen C. Pumpless extracorporeal lung assist ( $p E C L A)$ in patients with acute respiratory distress syndrome and severe brain injury. J Trauma. 2005;58:1294-7.

72. Robba C, Donnelly J, Bertuetti R, Cardim D, Sekhon MS, Aries M, et al. Doppler non-invasive monitoring of ICP in an animal model of acute intracranial hypertension. Neurocrit Care. 2015;23:419-26.

73. Godet T, Chabanne R, Marin J, Kauffmann S, Futier E, Pereira B, et al. Extubation failure in brain-injured patients. Anesthesiology. 2017;126:104-14.

74. Wang S, Zhang L, Huang K, Lin Z, Qiao W, Pan S. Predictors of extubation failure in neurocritical patients identified by a systematic review and metaanalysis. PLoS One. 2014;9:e112198.

75. Kutchak FM, Debesaitys AM, Rieder MM, Meneguzzi C, Skueresky AS, Forgiarini Junior LA, et al. Reflex cough PEF as a predictor of successful extubation in neurological patients. J Bras Pneumol. 2015;41:358-64.

76. Savi A, Teixeira C, Silva JM, Borges LG, Pereira PA, Pinto KB, et al. Weaning predictors do not predict extubation failure in simple-to-wean patients. J Crit Care. 2012;27:221 e1-8.

77. King CS, Moores LK, Epstein SK. Should patients be able to follow commands prior to extubation? Respir Care. 2010;55:56-65.

78. Wendell LC, Raser J, Kasner S, Park S. Predictors of extubation success in patients with middle cerebral artery acute ischemic stroke. Stroke Res Treat. 2011;2011:248789.

79. Cinotti R, Bouras M, Roquilly A, Asehnoune K. Management and weaning from mechanical ventilation in neurologic patients. Ann Transl Med. 2018;6:381.

80. Asehnoune $K$, Seguin P, Lasocki S, et al. Extubation success prediction in a multicentric cohort of patients with severe brain injury. Anesthesiology. 2017;127:338-46.

81. McCredie VA, Ferguson ND, Pinto RL, Adhikari NKJ, Fowler RA, Chapman $M G$, et al. Airway management strategies for brain-injured patients meeting standard criteria to consider extubation: a prospective cohort study. Ann Am Thorac Soc. 2017;14:85-93.

82. Bösel J, Schiller P, Hook Y, Andes M, Neumann JO, Poli S, Amiri H, Schönenberger S, Peng Z, Unterberg A, Hacke W, Steiner T. Stroke-related Early Tracheostomy versus Prolonged Orotracheal Intubation in Neurocritical Care Trial (SETPOINT): a randomized pilot trial. Stroke. 2013;44(1):21-8. https://doi.org/10.1161/STROKEAHA.112.669895. Epub 2012 Nov 29

83. Schönenberger S, Al-Suwaidan F, Kieser M, Uhlmann L, Bösel J. The SETscore to predict tracheostomy need in cerebrovascular neurocritical care patients. Neurocrit Care. 2016:25:94-104.

84. Schefold JC, Berger D, Zürcher P, Lensch M, Perren A, Jakob SM, et al. Dysphagia in mechanically ventilated ICU patients (dynamics): a prospective observational trial. Crit Care Med. 2017:45:2061-9.

85. Szeder V, Ortega-Gutierrez S, Ziai W, Torbey MT. The TRACH score: clinical and radiological predictors of tracheostomy in supratentorial spontaneous intracerebral hemorrhage. Neurocrit Care. 2010;13:40-6.

86. Steidl C, Bösel J, Suntrup-Krueger S, Schönenberger S, Al-Suwaidan F, Warnecke T, et al. Tracheostomy, extubation, reintubation: airway management decisions in intubated stroke patients. Cerebrovasc Dis. 2017;44:1-9.

87. McCann MR, Hatton KW, Vsevolozhskaya OA, Fraser JF. Earlier tracheostomy and percutaneous endoscopic gastrostomy in patients with hemorrhagic stroke: associated factors and effects on hospitalization. J Neurosurg. 2019;4:1-7.

88. McCredie VA, Alali AS, Scales DC, Adhikari NK, Rubenfeld GD, Cuthbertson $\mathrm{BH}$, et al. Effect of early versus late tracheostomy or prolonged intubation in critically ill patients with acute brain injury: a systematic review and metaanalysis. Neurocrit Care. 2017;26:14-25.

\section{Publisher's Note}

Springer Nature remains neutral with regard to jurisdictional claims in published maps and institutional affiliations. 